\title{
Building Bridges Between Education and Engineering Programs: An Example of a Successful Planning Process
}

\author{
Philip Parker, Jason Thrun \\ University of Wisconsin-Platteville
}

\section{Introduction}

Three Engineering faculty members and three School of Education faculty members at the University of Wisconsin-Platteville (UWP) have teamed up to introduce engineering fundamentals to pre-service teachers. The philosophy behind this project is that teacher education is the responsibility of the entire university, not simply the School of Education. As such, this project has four goals listed below. The first two goals focus on the pre-service teachers participating in the project and the second two goals are for the faculty involved:

a provide pre-service teachers with a basic understanding of the field of engineering so they are better able to describe the excitement of an engineering career to their future students;

- provide pre-service teachers with engineering applications that can enhance the learning of mathematics;

a introduce fundamental issues relating to engineering and engineering education to faculty members outside the field of engineering;

a improve pedagogy and teaching effectiveness of engineering faculty.

To meet these goals, we planned and implemented a model for an engineering experience for pre-service teachers. This experience pairs an existing 1-credit-hour class (GE1030 Introduction to Engineering Projects) with a bi-weekly seminar. The use of an existing course rather than an entirely new course is intended to make eventual implementation at UWP more likely.

This paper focuses on the intensive planning and professional development that occurred during the Summer of 2004 to implement the pilot offering of the GE1030 course and seminar to the pre-service teachers during the Fall 2004 semester. The implementation of this course is described in another paper presented at this conference.

\section{Planning Process}

The faculty team met nearly every week during the Summer of 2004. Prior to the summer, we had recruited students to the course. To recruit student volunteers, the project designers advertised a stipend of $\$ 750$ and a collection of resource books. The project was advertised in three ways. A letter describing the project was sent to students who were elementary/middle and secondary education majors with emphases in mathematics or science and who were 
participating an interview required for admittance into the school of education. Another letter was sent to a group of pre-service secondary mathematics education majors based on faculty recommendations. A final letter was given to mathematics and science education majors enrolled in methods courses.

To be eligible for consideration, a student must have junior standing and be admitted to the School of Education. Additionally, all applicants were required to write a one-page application letter that explained why they wanted to be part of the project and what they thought they could gain from the project. Nine mathematics education students applied and all were selected to participate in the experience.

The planning phase was designed to deal separately with faculty development and planning. As such, two distinct types of meetings were formed to address these needs: "Discussion Circles" and "Planning Councils." The intent of separating these two was to ensure that adequate time was devoted to investigating the state of the fields of engineering and education, and that the detailed planning of the Fall course would rely on this literature search.

In Discussion Circles, we discussed assigned readings at each meeting. The primary purpose of these meetings was originally intended to give the engineering faculty an opportunity to discuss the principles of engineering with the education faculty; however, these evolved into discussions on teaching and learning issues led primarily by the education faculty. The readings discussed by this group include the following:

Engineering literacy in high school students ${ }^{1,2}$

a Multiple intelligences ${ }^{3}$

- Wisconsin Model Academic Standards

- Massachusetts Teaching Standards

- National Education Technology Standards for Teachers

a American attitudes toward technology ${ }^{4}$

口 Teaching pedagogy,

- Learning styles ${ }^{7}$

- Current state of pre-college engineering ${ }^{8}$

․ Teamwork ${ }^{9,10,11}$

The Planning Councils were intended to ensure that the pilot offering was ready to be implemented at the start of the Fall semester. Tasks included:

- Review applicants

- Formulate assessment plan

- Obtain IRB approval

口 Register participants for the course

- Review and purchase books to begin participants' teaching library

- Create a list of expectations for pre-service teachers

口 Discuss teaching of GE1030

- Plan a kickoff meeting

a Compile 3-ring binder with materials/handouts for participants 
․ Create a schedule for Fall seminar

\section{Major Outcomes and Findings of Planning Process}

There is a paucity of published studies pairing engineering and education.

We found it difficult to find published works to review in the Discussion Circle where engineering and education faculty formed partnerships. Two papers were discussed ${ }^{1,2}$ that provided helpful insight. However, these papers also revealed that there is not a validated survey instrument to measure student satisfaction and interest in engineering. Moreover, these papers discussed the creation of an entirely new course at the University of Nevada, Reno and reinforced for us that our focus on an existing course is a more viable and more easily adopted option.

We proposed a hierarchy for methods of integrating engineering and education.

Although engineering and education faculty at universities typically do not work closely together, there has been a plethora of activities in which the engineering field has reached out to the K-12 classroom. These are nicely summarized by Sullivan ${ }^{8}$ and include engineering student presentations/demonstrations in the classroom, summer camps for students, summer workshops for K-12 educators, etc. All of these activities have the potential to positively impact the awareness of engineering by K-12 students. However, a poorly-run or ill-planned activity could have a negligible impact or could lead to negative perceptions of the field. Moreover, not all outreach activities will positively impact teacher awareness of engineering in a meaningful way, nor will they positively affect the teaching and learning of the essential (to engineering) subjects of mathematics and science. In response to this review, the team proposes a hierarchy of integrating engineering into the K-12 environment. It must be stressed that any activity on this hierarchy is potentially beneficial and can have positive impacts if it is carefully planned and coordinated; however, we feel that the higher level activities are more meaningful and are more able to effectively create a lasting and positive impact on the field of engineering.

Level 1: Outreach activities by engineering students/faculty/staff in K-12 classroom.

Level 2: $\quad$ Summer engineering experience for K-12 students (e.g. camp)

Level 3: Teaching pre-service teachers about engineering

Level 4: Requiring pre-service teachers to create engineering lesson plans in which the students will do engineering.

Level 5: Require pre-service teachers to use the engineering lesson plans prior to leaving college.

We noted that the vast majority of projects integrating engineering into the K-12 classroom stop at Level 1. Level 3 is practiced very rarely (e.g. see Robinson and Kenny, 2003; Robinson et al., 1999). The pilot project discussed in this paper went as far as Level 4. 
Ideally, the five levels would be linked to engineering standards. Massachusetts has led the way among states by incorporating a set of engineering standards. However, it is not clear whether they have trained the teachers (Levels 3-5) to ensure success of the integration.

The word "engineering" is absent from Wisconsin state standards on mathematics.

We investigated the Massachusetts Science and Technology/Engineering Curriculum Framework and were greatly impressed by the ambitious scope of the standards. We compared these standards to the Wisconsin standards for mathematics and science. While the Wisconsin standards never mentioned the word "engineering," the engineering faculty members on the team clearly saw that nearly every standard could readily be enhanced through engineering applications. Moreover, many of the "applied" science and mathematics topics are actually engineering topics without being termed as such.

Based on studying the standards and our own observations, there appears to be tremendous potential to raise the awareness of engineering in the K-12 classroom, in many cases using existing projects and materials. Two team members noted that their school-age children completed several engineering-type projects in a variety of courses, including optimizing a tower of books as part of a project in Social Studies. In all cases, the word engineering was never used, yet these activities could clearly have been termed "engineering applications."

We created a generic model for effective planning activities.

All faculty members greatly enjoyed the summer of planning and development. We listed some attributes of our summer sessions that made it so successful. In no particular order, those attributes are listed below.

口 Limit (but don't necessarily eliminate) "soapbox speeches"

- Avoid complaining about students

- Don't interrupt one another

- Prepare for the meetings

- Avoid dominating the conversation with your favorite anecdotes

- Base observations on published theory, not only on instinct or "common sense"

- Compile a group that cares about the topic

- Financial compensation seems necessary but is not sufficient for success

We created a model for implementing a course to teach engineering to pre-service teachers.

Planning the details was critical to the success of this project, such that on the first day of the semester, we were ready to begin. This sent the message to the students that we were prepared, organized, and taking this project seriously.

We planned to start off the semester with a "kick-off" meeting, where faculty team members and students could introduce themselves. We also would attend to administrative details such as providing the students with their $\$ 750$ stipend; setting bi-weekly seminar dates for 
the Fall 2004 semester; providing students with a list of expectations; and discussing the first journaling assignment.

For the pilot offering, students would enroll in a single section of GE1030. They would "share" this section with 24 beginning engineering students. The course consists of completing engineering projects in teams, and after some discussion we decided to mix the pre-service teachers into teams with the engineering students rather than have "homogenous" teams of only engineering students or only education students. We hoped that the heterogeneous teams would allow us to readily compare the two different groups of students, as well as allow the pre-service teachers to observe the engineering students.

Pre-service teachers would be given the same assignments as the engineering students enrolled in GE1030 with one exception. Rather than complete the term paper (a literature review of a major engineering accomplishment), the pre-service teachers would prepare a set of lesson plans for their future classroom based on an engineering project. We drew up a set of guidelines for the lesson plans, which are found in the Appendix. We believe that this requirement of the pre-service teachers is an innovative idea and will greatly improve the chances of the pre-service teachers sharing engineering principles in their classroom. The budget for the project also allowed students to buy $\$ 300$ of supplies to support their project. Again, this will greatly improve chances of implementation. In addition, we purchased nine books for the students.

We also planned for the pre-service teachers to meet with the six faculty in bi-weekly seminars during the Fall semester. In each seminar, selected student journal entries would be shared anonymously with the group and discussed. Also, an additional topic would be discussed in each seminar. The planned topics included:

- Potential implementation of GE1030 projects in the pre-service teachers' future classroom

- Wisconsin Math/Science standards

- Format and content of lesson plans

口 Feedback on progress of GE1030

a Multiple intelligences

- Administrative details

口 Possibility of requiring the GE1030/BEE Seminar of all Mathematics Education majors at UWP.

We created an Assessment Plan for the pilot project

The assessment plan we created consisted of the following:

a An engineering attitude survey to be administered to all students in all GE1030 sections and to 20 education students not enrolled in GE103 at the start of the Fall 2004 semester. At the end of the semester, the same survey would be administered to students in the pilot section of GE1030. 
- All students in the pilot section of GE103 would take a "Learning Style Assessment" and a Technological Literacy survey at the beginning of the semester.

a Pre-service teachers that had heard about the pilot offering but had chosen not to participate will be contacted by phone.

- Students will keep submit weekly journal entries.

- Student performance on projects and final exam will be noted.

- Lesson plans will be evaluated.

\section{Summary}

In retrospect, the planning was a very rewarding experience for all faculty involved. Engineering faculty learned that there were subject experts on pedagogy within the same university. Education faculty gained an appreciation of the engineering profession. The major outcomes listed in this paper formed the basis of a highly successful experimental offering in Fall 2004 (see companion paper).

There are several keys to the success of the planning phase. The primary key to success may simply be in setting aside time in the summer to meet with a group of faculty. In addition, the faculty must be knowledgeable, enthusiastic, and committed to improving student learning. Moreover, it was very helpful having a diverse group of faculty to provide diverse perspectives which helped greatly in the brainstorming that occurred throughout the summer. Another key to success was separating the theoretical discussions (Discussion Circles) from the practical discussions (Planning Councils) and basing the latter on the former. Moreover, by mixing these topics throughout the planning period was beneficial as compared to discussing only one topic for half the semester and then moving on to the next topic. The Discussion Circle's success lay partly in the fact that each member was allowed to select a topic that they viewed as pertinent and important, and also was in their area of expertise. Finally, being financially compensated was also very helpful.

\section{Acknowledgment}

The authors gratefully acknowledge the support of the National Science Foundation's Bridging Engineering Education (BEE) program. The BEE program supported this study through funding of "Creating a Framework to Enhance the Engineering Literacy of Education Majors and the Instructional Effectiveness of Engineering Faculty" (Award \# EEC-0341962).

Bibliography

${ }^{1}$ Robinson, M. and B. Kenney. "Engineering Literacy in High School Students.” Bulletin of Science, Technology, and Society 23(2), 95-101.

2 Robinson, M, M. Sami Fadali, J. Carr, and C. Maddux (1999). “Engineering Principles for High School Students.” Proceedings of the $29^{\text {th }}$ ASEE/IEEE Frontiers in Education Conference, November $110-13$, 1999, San Juan Puerto Rico. P. 13a7-20 - 13a7-25.

${ }^{3}$ Gardner, H. and T. Hatch (1989). "Multiple Intelligences Go to School: Educational Implications of the Theory of Multiple Intelligences" Educational Researcher, 18(8) p. 4-10. 
${ }^{4}$ International Technology Education Association Bulletin (2002). "ITEA/Gallup Poll Reveals What Americans Think About Technology.” March 2002.

${ }_{6}^{5}$ Joyce, B.R., M. Weil, and E. Calhoun (2003). Models of Teaching, Seventh Edition. Allyn \& Bacon, 552 p.

${ }^{6}$ Skemp, R.R. (1978). "Relational Understanding and Instrumental Understanding." Mathematics Teaching 26(3), p. 9-15.

${ }^{7}$ Felder, R.M. and B.A. Soloman (2004). "Learning Styles and Strategies," Accessed from www.ncsu.edu/felder public/ILSdir/styles.htm on June 2, 2004.

${ }^{8}$ Sullivan, J.F. (2004). "Pre-College Engineering: The Future is in Our Hands." Keynote address delivered at 2004 ASEE Annual Conference and Exposition.

${ }^{9}$ Breslow, L. (1998). "Teaching Teamwork Skills," Teach Talk Articles, 10(4). accessed from web.mit.edu/tll/published/teamwork1.htm on 7/14/04.

${ }^{10}$ Page, D. and J.G. Donelan. "Team-Building Tools for Students." Journal of Education for Business, January/February 2003, p. $125-128$.

${ }^{11}$ Hirsch, P, B. Shwom, and A. McKenna. "Teaching and Assessing Teamwork: Implementing Continuous Quality Improvement." Proceedings of the 2003 Association for Business Communication Annual Convention.

Biographical Information

Dr. Philip Parker (parkerp@uwplatt.edu) is an Associate Professor at the University of Wisconsin-Platteville. He received his B.S, M.S., and Ph.D. from Clarkson University in Potsdam, NY. His teaching interests span the Environmental Engineering field. He is past Program Chair for the ASEE Environmental Engineering Division.

Dr. Jason Thrun (thrunj@uwplatt.edu) is an Associate Professor in the Mathematics Department at the University of Wisconsin-Platteville. He received his B.S from the University of Illinois and M.S. and Ph.D. from Northern Illinois University. In addition to other undergraduate courses, he teaches many courses for pre-service teachers preparing to teach elementary and middle school. 